\title{
Evaluation of nutritional and economic feed values of spent coffee grounds and Artemisia princeps residues as a ruminant feed using in vitro ruminal fermentation
}

Jakyeom Seo, Jae Keun Jung, Seongwon Seo

Much research on animal feed has focused on finding alternative feed ingredients that can replace conventional ones (e.g., grains and beans) to reduce feed costs. The objective of this study was to evaluate the economic, as well as nutritional value of spent coffee grounds (SCG) and Japanese mugwort (Artemisia princeps) residues (APR) as alternative feed ingredients for ruminants. We also investigated whether pre-fermentation using Lactobacillus spp. was a feasible way to increase the feed value of these by-products. Chemical analyses and an in vitro study were conducted for SCG, APR, and their prefermented forms. All the experimental diets for in vitro ruminal fermentation were formulated to contain a similar composition of crude protein, neutral detergent fiber and total digestible nutrients at $1 x$ maintenance feed intake based on the dairy National Research Council (NRC). The control diet was composed of ryegrass, corn, soybean meal, whereas the treatments consisted of SCG, SCG fermented with Lactobacillus spp. (FSCG), APR, and its fermented form (FAPR). The treatment diets replaced $100 \mathrm{~g} / \mathrm{kg}$ dry matter (DM) of the feed ingredients in the control. Costs were lower for the all treatments, except FAPR, than that of the control. After 24-h incubation, the NDF digestibility of the diets containing SCG and its fermented form were significantly lower than those of the other diets $(P<0.01)$; pre-fermentation tended to increase NDF digestibility $(P=0.07$ ), especially for APR. Supplementation of SCG significantly decreased total gas production $(\mathrm{ml} / \mathrm{g} \mathrm{DM})$ after 24-h fermentation in comparison with the control $(P<0.05)$; however, there were no significant differences between the control and the SCG or the APR diets in total gas production, as expressed per Korean Won (KRW). Diets supplemented with SCG or FSCG tended to have a higher total volatile fatty acid (VFA) concentration, expressed as per KRW, compared with the control $(P=0.06)$. Conversely, the fermentation process of SCG and APR significantly decreased total gas production and VFA production as expressed per KRW $(P<0.05)$. Because of their nutrient composition and relatively lower cost, we concluded that SCG and APR could be used as alternative feed sources, replacing conventional feed ingredients. However, pre-fermentation of agricultural by-products, such as SCG and APR, may be inappropriate for improving their nutritive considering the 
increase in production costs. 


\section{1}

2

3

\section{Evaluation of nutritional and economic values of spent coffee grounds and Artemisia} princeps residues as a ruminant feed using in vitro ruminal fermentation

$$
\text { Jakyeom Seo }{ }^{1,2} \text {, Jae Keun Jung }{ }^{1} \text {, and Seongwon Seo }{ }^{1, a}
$$

${ }^{1}$ Department of Animal Biosystem Sciences, Chungnam National University, Daejeon 305-764,

6

\section{Republic of Korea}

${ }^{2}$ Life and Industry Convergence Research Institute, Department of Animal Science, Pusan National University, Miryang 627-706, Republic of Korea

(1)

(1)

4 a Corresponding author:

\section{Seongwon Seo}

Address: 99 Daehak-ro, Yuseong-gu, Daejeon 305-764, Republic of Korea

Email: swseo@cnu.kr

Phone: $+82-42-821-5787$

Fax: $+82-42-823-2766$ 


\section{Abstract}

Much research on animal feed has focused on finding alternative feed ingredients that can replace conventional ones (e.g., grains and beans) to reduce feed costs. The objective of this study was to evaluate the economic, as well as nutritional value of spent coffee grounds (SCG) and Japanese mugwort (Artemisia princeps) residues (APR) as alternative feed ingredients for ruminants. We also investigated whether pre-fermentation using Lactobacillus spp. was a feasible way to increase the feed value of these by-products. Chemical analyses and an in vitro study were conducted for SCG, APR, and their pre-fermented forms. All the experimental diets for in vitro ruminal fermentation were formulated to contain a similar composition of crude protein, neutral detergent fiber (NDF) and total digestible nutrients at 1x maintenance feed intake based on the dairy National Research Council (NRC). The control diet was composed of ryegrass, corn, soybean meal, whereas the treatments consisted of SCG, SCG fermented with Lactobacillus spp. (FSCG), APR, and its fermented form (FAPR). The treatment diets replaced $100 \mathrm{~g} / \mathrm{kg}$ dry matter (DM) of the feed ingredients in the control. Costs were lower for the all treatments, except FAPR, than that of the control. After 24 hour (h) incubation, the NDF digestibility of the diets containing SCG and its fermented form were significantly lower than those of the other diets $(P<0.01)$; pre-fermentation tended to increase NDF digestibility $(P=$ 0.07), especially for APR. Supplementation of SCG significantly decreased total gas production $(\mathrm{ml} / \mathrm{g} \mathrm{DM})$ after $24 \mathrm{~h}$ fermentation in comparison with the control $(P<0.05)$; however, there were no significant differences between the control and the SCG or the APR diets in total gas production, as expressed per Korean Won (KRW). Diets supplemented with SCG or FSCG tended to have a higher total volatile fatty acid (VFA) concentration, expressed as per KRW, compared with the control $(P=0.06)$. Conversely, the fermentation process of SCG and APR 
48 significantly decreased total gas production and VFA production as expressed per KRW $(P<$

49 0.05). Because of their nutrient composition and relatively lower cost, we concluded that SCG

50 and APR could be used as alternative feed sources, replacing conventional feed ingredients.

51 However, pre-fermentation of agricultural by-products, such as SCG and APR, may be

52 inappropriate for improving their nutritive considering the increase in production costs.

53

54

55

56

\section{Introduction}

Research on animal feed has often focused on finding alternative feed ingredients to replace conventional ones (e.g., grains and beans) in order to reduce feed costs. This is most important in developing countries where the supplies of cereal grains and beans are not great enough to support even the human population. Historically, by-products from processing crops and food products have received much attention as feed alternatives because of their consistent and mass production. Food by-products would also likely be inexpensive because of their classification as a waste product. Many by-products, however, do not contain enough nutrients to support livestock requirements, and their palatability and digestibility would need to be enhanced, even for ruminants. Pre-fermentation of these by-products by bacteria (Kim et al., 2012), yeast (Wanapat et al., 2011), or fungi (Salman et al., 2008) are common methods to enhance their nutritional value (see Mahesh and Mohini [2013] for a review).

Although fermentation may improve the nutritional quality of the by-products, and it is an environmentally sustainable practice, it will increase the cost for feed production. This additional cost is often ignored by researchers. To make the fermentation process feasible, the production costs of a fermented by-product must to be competitive with conventional feed ingredients 
70 (Wanapat et al., 2013). Therefore, the economic value, as well as nutritional value, of fermented

\section{0} by-products must be considered simultaneously.

In this study, we evaluated the economic and nutritional values of spent coffee grounds (SCG) and Japanese mugwort (Artemisia princeps) residues (APR), as well as their fermented products as potentially cost-effective feed ingredients for ruminants. An in vitro ruminal fermentation study where Total mixed rations (TMR) was supplemented with SCG or APR was conducted. These by-products were chosen primarily because of the rapid increase of production, and the relatively high content of nutrients and bio-active compounds. SCG are generated during the manufacture of instant coffee. It is the residue that remains after brewing raw coffee powders with hot water or steam. Annually, 6-million tons of SCG are produced worldwide and most of it is burned as waste, resulting in greenhouse gas emissions (Tokimoto et al., 2005). There have been studies on the potential of SCG as a feed source for ruminants (Campbell et al., 1976; Bartley et al., 1978; Givens and Barber, 1986; Xu et al., 2007) and even for monogastric animals (Sikka et al., 1985; Sikka and Chawla, 1986). Xu et al. (2007) concluded that wet coffee grounds could be included up to $100 \mathrm{~g} / \mathrm{kg}$ on a dry matter (DM) basis in total mixed rations (TMR) for goats. APR is a by-product from the traditional Korean medicine industry; it is produced during harvesting and processing of leaves. Positive effects were observed in growth performance of broilers supplemented by Lactobacillus-fermented APR (Kim et al., 2012). To the best of our knowledge, however, there has been no attempt to assess the feasibility of fermented SCG or APR as a feed alternative in ruminants based on both their nutritional and economic values. 91

\section{Materials and methods}


93 Two cannulated non-lactating Holstein cows at Center for Animal Science Research, Chungnam

94 National University, Korea were used in this study. Animal use and the protocols for this 95 experiment were reviewed and approved by the Chungnam National University Animal Research 96 Ethics Committee (CNU-00455).

\subsection{Preparation of experimental diets}

The feed ingredients used in this study were ryegrass, corn, soy bean meal (SBM), SCG, APR, and the Lactobacillus-fermented forms of SCG and APR (FSCG and FAPR, respectively). SCG were purchased from an instant coffee manufacturer (Dongseo Food, Inc., Bupyeong, Korea), and APR was obtained from the Ganghwa Agricultural R\&D Center (Incheon, Korea). The fermentation process for SCG and APR with Lactobacillus spp. was conducted as described by Kim et al. (2012). Briefly, four strains of Lactobacillus spp. (L. acidophilus ATCC 496, L. fermentum ATCC 1493 [American Type Culture Collection: Virginia, USA], L. plantarum KCTC 1048 [Korean Collection Type Culture, Daejeon, Korea], and L. casei IFO 3533 [Korea Food Research Institute, Daejeon, Korea]) were used to ferment SCG and APR. A 11 culture medium was inoculated with a $2 \mathrm{ml}$ aliquot containing $10^{9} \mathrm{cfu} / \mathrm{ml}$ of each Lactobacillus strain (de Man, Rogosa, and Sharpe broth [Difco Laboratories, Francisco Soria Melquizo S.A., Madrid,

110 Spain], $10 \mathrm{~g}$; sucrose, $10 \mathrm{~g}$ ) and incubated at $36^{\circ} \mathrm{C}$ for 24 hour (h). Next, $4 \mathrm{~kg}$ of dried SCG and 111 APR were mixed with $400 \mathrm{ml}$ of prepared Lactobacillus inoculum in a fermentation flask and 112 incubated for $72 \mathrm{~h}$ at $36^{\circ} \mathrm{C}$. The fermented by-products were obtained after freeze-drying the 113 cultured substrate and media for 2 days following the manufacture's recommendations 114 (ilShinBioBase, Inc., Korea). 
115 All of the diets that included in vitro fermentation were formulated to meet nutrient

116 requirements for non-lactating dairy cows (total digestible nutrient at 1x maintenance feed intake

117 [TDN1x], $680 \mathrm{~g} / \mathrm{kg}$; crude protein [CP], $120 \mathrm{~g} / \mathrm{kg}$; neutral detergent fiber [NDF], $420 \mathrm{~g} / \mathrm{kg}$ on a

118 DM basis) according to the National Research Council (NRC 2001). The control diet was

119 composed of $500 \mathrm{~g} / \mathrm{kg}$ of ryegrass and $500 \mathrm{~g} / \mathrm{kg}$ of a corn and SBM mix. The four experimental

120 diets (SCG, FSCG, APR, and FAPR) were formulated to contain TDN1x, CP, and NDF contents

121 (g/kg DM) similar to the control, replacing original ingredients with $100 \mathrm{~g} / \mathrm{kg} \mathrm{DM}$ of SCG,

122 FSCG, APR or FAPR, respectively.

123

\subsection{In vitro incubation}

125 Rumen fluid was collected before the morning feeding from two cannulated non-lactating

126 Holstein cows fed a ration consisting of $600 \mathrm{~g} / \mathrm{kg}$ timothy hay and $400 \mathrm{~g} / \mathrm{kg}$ of a commercial

127 concentrate mix $(123 \pm 8.8 \mathrm{~g} / \mathrm{kg} \mathrm{CP}, 35 \pm 6.4 \mathrm{~g} / \mathrm{kg}$ ether extract [EE], $265 \pm 6.9 \mathrm{~g} / \mathrm{kg} \mathrm{NDF}$, and

$128109 \pm 1.2 \mathrm{~g} / \mathrm{kg}$ ash) twice daily at the Center for Animal Science Research, Chungnam National

129 University, Korea. The rumen contents were mixed and transferred into a thermos bottle, and

130 immediately transported to the laboratory. Rumen contents were strained through 4 layers of

131 cheesecloth and mixed with $4 \mathrm{x}$ volumes of in vitro rumen buffer solution (Goering and Van

132 Soest, 1970) under strictly anaerobic conditions. Fifty $\mathrm{ml}$ of rumen fluid/buffer mixture was

133 transferred into $125 \mathrm{ml}$ serum bottles containing $0.5 \mathrm{~g}$ of experimental diets under continuous

134 flushing with $\mathrm{O}_{2}$-free $\mathrm{CO}_{2}$ gas. The bottles were sealed with butyl rubber stoppers and aluminum 135 caps, and incubated for $0,3,6,9,12,24$, and $48 \mathrm{~h}$ at $39^{\circ} \mathrm{C}$. 
138

139

140

141

142

143

144

145

146

147

148

149

150

151

152

153

154

155

156

157

158

159

160

\subsection{Analyses}

Contents of DM (\#934.01), CP (\#976.05), EE (\#920.39), lignin (ADL; \#973.18) and ash (\#942.05) in the feed samples were determined as described by AOAC (2005). NDF, analyzed using a heat stable amylase and expressed inclusive of residual ash, and acid detergent fiber (ADF) were determined as described by Van Soest et al. (1991). Neutral detergent insoluble crude protein (NDICP) and acid detergent insoluble crude protein (ADICP) were determined as described by Licitra et al. (1996). Non-fiber carbohydrate (NFC) was calculated as 1000-CP-EEAsh-(NDF-NDICP) based on NRC (2001).

For phenolic acid analysis, caffeic acid, p-coumaric acid, ferulic acid, and sinapic acid (Sigma-Aldrich, Missouri, USA; \# C0625, \# C9008, \# 12870, and \# D7927, respectively) were used as standards. Identification of phenolic acids in the SCG and APR samples was based primarily on retention time, UV spectra obtained from high-performance liquid chromatography (HPLC-DAD), and mass spectrometric data using authentic standards. Phenolic acids were analyzed as described by Rochfort et al. (2006).

After each incubation period, total gas production was measured using a pressure transducer (Sun Bee Instruments, Inc., Seoul, Korea) as described by Theodorou et al. (1994). Next, 5 ml of head space gas was collected using a gas tight syringe (Hamilton, Reno, Nevada, USA) for analysis of $\mathrm{CH}_{4}$ using a gas chromatograph (Daesung Science IGC-7200, Seoul, Korea) equipped with a thermal conductivity detector and HayeSep Q 80/100 column (Restek, Bellefonte, Pennsylvanian, US). The $\mathrm{pH}$ of the cultured fluid was measured with a general purpose $\mathrm{pH}$ meter (Istek Inc., Seoul, Korea). The cultured fluid was then centrifuged at 14,000 rpm for $10 \mathrm{~min}$ at $4^{\circ} \mathrm{C}$, and the supernatant was used for the analyses of volatile fatty acid (VFA) and ammonia concentrations. The remaining undegraded samples and fluid were analyzed for NDF using a 
161 modified version of the micro-NDF method proposed by Pell and Schofield (1993) for

162 measuring NDF degradability. VFA concentrations were determined as described by Erwin et al.

163 (1961). Ammonia concentration was analyzed by the method of Chaney and Marbach (1962).

164 For the economic analysis, the price of each feed ingredient was estimated and expressed in 165 Korean won (KRW). The average market prices of ryegrass, corn, and SBM in 2009 were used 166 (i.e., 364, 317, and $660 \mathrm{KRW} / \mathrm{kg} \mathrm{DM}$, respectively). The prices of SCG and APR (i.e., 91 and $167235 \mathrm{KRW} / \mathrm{kg} \mathrm{DM}$, respectively) were obtained from the respective manufacturers. Prices of FSCG and FAPR (i.e., 270 and $429 \mathrm{KRW} / \mathrm{kg}$ DM, respectively) were calculated by adding SCG and APR prices to the cost for the fermentation process (i.e., $200 \mathrm{KRW} / \mathrm{kg}$ as fed). The cost of the fermentation process included expenses for microbial strains, culture medium, labor, use of

171 fermenter instruments, and manufacturing.

172

173

\subsection{Statistical analysis}

174 The experiment was conducted using a completely randomized design, and the data were analyzed using the GLM procedure of SAS (SAS Institute Inc., Carey, North Carolina, USA) as:

$$
y_{i j}=\mu+\tau_{i}+e_{i j}
$$

Where: $y_{i j}$ is the $j$ th observation in the $i$ th treatment, $\mu$ is the overall mean, $\tau_{i}$ is the fixed effect of

178 the $i$ th treatment ( $i=1$ to 5 ), and $e_{i j}$ is the unexplained random effect on the $j$ th observation in

179 the $i$ th treatment. Four contrasts were tested: the difference between the control and SCG

180 (control versus SCG and FSCG), control and APR (control versus APR and FAPR), SCG and

181 APR (SCG and FSCG versus APR and FAPR), and non-fermented and fermented groups (SCG

182 and APR versus FSCG and FAPR). Differences among treatments were also compared with the 
183 Tukey's test when there was a significant overall treatment effect. Statistical significance was

184 defined as $P<0.05$, and a trend was discussed at $0.05 \leq P<0.10$.

185

186

\section{Results}

Both by-products had higher amounts of fiber and lower NFC compared with corn or SBM, and SCG had a markedly high level (>100 g/kg DM) of EE (Table 1). Phenolic acid contents of SCG and APR were 3.22 and $2.80 \mathrm{mg} / \mathrm{g}$ DM, respectively. More specifically, the concentrations of caffeic acid, $p$-coumaric acid, ferulic acid, and sinapic acid were 1.07, 0.42, 1.70, and 0.04 $\mathrm{mg} / \mathrm{g} \mathrm{DM}$ and 1.72, 0.77, 0.32, and 0.00 in SCG and APR, respectively. The fermentation process increased feed cost and decreased NFC contents in both by-products (Table 1). The fermentation process also increased NDF content.

All the experimental diets for the in vitro fermentation contained similar TDN1x (677-683 $\mathrm{g} / \mathrm{kg} \mathrm{DM}), \mathrm{CP}$ (120 g/kg DM), and NDF (423-444 g/kg DM) contents (Table 2), and their prices were calculated based on the prices of each feed ingredient (Table 1) and the formulated ratio of respective treatments (Table 2). The Korea Won was the unit to estimate cost of experimental diets. Compared to the control diet, inclusion of the by-products reduced the price of formulated diet (14-30 KRW/kg DM), except for FAPR which increased the price by $4 \mathrm{KRW} / \mathrm{kg}$ DM (Table

2). The use of fermented by-products increased the cost of diets by 6 to $20 \mathrm{KRW} / \mathrm{kg} \mathrm{DM}$.

201 Supplementation of APR or FAPR significantly reduced $\mathrm{pH}$ compared to other treatments $(P$ $202<0.01$, Table 3). Ammonia nitrogen concentration did not differ among treatments. NDF 203 digestibility of the SCG group was significantly lower than that of the other diets $(P<0.01)$ and 204 the fermentation process tended to increase NDF digestibility $(P=0.07)$, especially that of APR $205(P<0.05$, Table 3). Compared to the control diet, supplementation of SCG significantly 
206 decreased total gas production $(\mathrm{ml} / \mathrm{g} \mathrm{DM})$ after $24 \mathrm{~h}$ fermentation $(P<0.05$, Table 3$)$. The 207 fermentation process of SCG and APR tended to decrease total gas production $(P=0.10)$ and 208 significantly decreased total gas production per KRW (ml/KRW). No statistical difference in

$209 \mathrm{CH}_{4}$ production (ml/g DM) was observed among treatments; however, there was a tendency for a 210 decrease in $\mathrm{CH}_{4}$ production with SCG supplementation as compared to that of APR $(P=0.07)$.

211 Significant differences were not detected in total VFA production (mmol/g DM), proportion of 212 acetate $(\mathrm{mmol} / \mathrm{mol})$, proportion of propionate $(\mathrm{mmol} / \mathrm{mol})$, or acetate:propionate ratio. The diet 213 supplemented with SCG or FSCG; however, tended to have a higher total VFA concentration per 214 KRW (mmol/KRW) compared to the control $(P=0.06)$. Moreover, the fermentation process of 215 SCG and APR significantly decreased total VFA production (mmol/KRW) $(P<0.05)$. There 216 were significant differences among the experimental diets in the proportion of butyrate $(P<0.01$, 217 Table 3).

\section{4. Discussion}

This study was designed to evaluate the nutritional and economic value of two food byproducts, SCG and APR, as alternatives to conventional feed ingredients, and to investigate whether the pre-fermentation of these by-products using Lactobacillus spp. could be an economically feasible practice for increasing their nutritional value. These by-products were chosen primarily because of the rapid increase in their production, and their relatively high content of nutrients and bio-active compounds (Wallace, 2007; Acevedo et al., 2013). It was expected that the bio-active phenolic compounds contained in these by-products would modulate rumen microbial activity, fermentation characteristics, and $\mathrm{CH}_{4}$ emission (Acevedo et al., 2013;

Kim et al., 2013). Fermentation of selected by-products using Lactobacillus spp. was applied to 
229 improve their nutritive values as feed ingredients. However, a dramatic increase of CP by 230 microbial proliferation was not observed in either fermented by-products (Table 1), indicating

231 that phenolic compounds, such as tannins, appear to be resistant to cell wall degradation by 232 microbial inoculants. The decrease in NFC contents observed in fermented by-products (Table 1) 233 indicated that the inoculated microbes might utilize non fiber sugars in both by-products during 234 fermentation period. Both NDICP and ADICP contents were high in SCG, which might be 235 caused by the Maillard reaction that occurs during beverage production under high temperature 236 (Senevirathne et al., 2012).

237 The use of SCG and APR could decrease the price of diets with similar nutrient contents. Formulated experimental diets using SCG, FSCG, and APR had lower feed cost than the control diet without compromising $\mathrm{CP}, \mathrm{NDF}$, or TDN1x contents; however, the experimental diet using FAPR did not (Table 2). This result suggested that the residues (except those of FAPR) may be applied to feed formulation to achieve economic advantages; however, lower NFC and higher EE contents observed in diets having SCG compared to the control diet should be considered when SCG is applied to practical feed formulation. The supplementation fat source can increase energy density in diets but the excessive fat addition limits rumen fermentation, intestinal nutrients absorption (Palmquist, 1994). Because of different nutrient compositions between SCG and APR, SCG tends to replace energy and protein sources, whereas APR replaces forage. Thus, supplementation of SCG is more favorable when the price of protein sources is high, whereas APR would be a more appropriate alternative when the price of forage is high. Both SCG and APR are feed ingredient alternatives for ruminants, particularly if the goal is to reduce feed cost. 
252 aspects. Lower gas production observed in SCG treatments than that of the control could have 253 been caused by lower NFC contents compared to the control diet, although they had similar 254 composition in regard to CP, NDF, and TDN1x. Seo et al. (2009) reported that total gas 255 production at $48 \mathrm{~h}$ was primarily determined by the NFC content. The diets containing SCG had 256 significantly lower NDF digestibility than the other diets. It was speculated that such phenolic 257 compounds and resistance factors from the Maillard reaction in SCG might be associated with in 258 vitro digestibility (Puchala et al., 2005; Senevirathne et al., 2012). More importantly, there was no significant difference between the control and the SCG supplemented diets in gas production as expressed by $\mathrm{ml} / \mathrm{KRW}$, which implied replacement of conventional feed ingredients by SCG could be economically beneficial without compromising ruminal fermentation.

Regarding VFA concentration, diets using APR exhibited a tendency toward increased VFA production at $24 \mathrm{~h}$ fermentation compared to SCG (Table 3). Meanwhile, VFA production based on price $(\mathrm{mmol} / \mathrm{KRW})$ tended to be higher in samples using SCG than the control group, indicating the use of SCG as the alternative feed source might not cause any negative effects on rumen fermentation. Xu et al. (2007) indicated that the proportion of SCG in TMR should not exceed $10 \%$ of DM. Lower nutrient digestibility and VFA production were observed when $20 \%$ of SCG was added to TMR in their study. However, since nutrient composition between treatments was not controlled in their studies, the optimal concentration of SCG that could be included in ruminant diets should be tested in terms of both nutritional and economical aspects as described in this study.

272 Based on the results from in vitro ruminal fermentation, the pre-fermentation process in this study is unlikely a feasible practice to improve the nutritional value of SCG and APR. Although 274 pre-fermentation increased NDF digestibility of APR, there was a significant decrease in VFA 
275 production in fermented treatments when expressed based on costs $(\mathrm{mmol} / \mathrm{KRW})$. A declining 276 tendency in total gas production was also observed in the pre-fermentation of the by-products.

277 This implies that fermented by-products may not be appropriate as feed alternatives in terms of 278 cost-effectiveness, even though they have a potential to be a feed additive having probiotic 279 functions that include modulation of ruminal fermentation, enhanced fiber digestion, and 280 immune stimulation in the hind-gut (McAllister et al., 2011).

281 A previous in vitro study using beverage residues found that TMR using SCG had similar $282 \mathrm{CH}_{4}$ production to the control, whereas, both TMRs showed significantly decreased $\mathrm{CH}_{4}$ 283 production compared to the other TMR using green tea residues (Senevirathne et al., 2012). In 284 this study, $\mathrm{CH}_{4}$ production was numerically decreased in the diet formulated with SCG compared 285 to the control; nevertheless, further research to investigate the effect of SCG usage on rumen 286 fermentation is required because it might have considerable amounts of polyphenolic compounds 287 that can modulate $\mathrm{CH}_{4}$ emission (Puchala et al., 2005), nitrogen metabolism, and the rumen 288 protozoal population (Wallace, 2007).

\section{Conclusions}

The results of this study indicated that SCG and APR may be used as alternatives to conventional feed ingredients because of their nutrient composition and relatively low cost. Prefermentation of these products, however, may be inappropriate for improving their nutritional content considering the increase in production costs. Further studies on in vivo ruminal fermentation, and whole body digestion and metabolism by supplementing these by-products are warranted.

\section{References}


299 Acevedo, F., Rubilar, M., Scheuermann, E., Cancino, B., Uquiche, E., Garcés, M., Inostroza, K.,

300 Shene, C., 2013. Spent coffee grounds as a renewable source of bioactive compounds. J.

301 Biobased Mater. Bio. 7, 420-428.

302 AOAC, 2005. Official Methods of Analysis of AOAC International. Association of Official 303 Analytical Chemists International, Gaithersburg, MD, USA.

304 Bartley, E.E., Ibbetson, R.W., Chyba, L.J., Dayton, A.D., 1978. Coffee grounds. II. Effects of 305 coffee grounds on performance of milking dairy cows and feedlot cattle, and on rumen 306 fermentation and dry matter removal rate. J. Anim. Sci. 47, 791-799.

307 Campbell, T.W., Bartley, E.E., Bechtle, R.M., Dayton, A.D., 1976. Coffee grounds. I. Effects of 308 coffee grounds on ration digestibility and diuresis in cattle, on in vitro rumen fermentation, and 309 on rat growth. J. Dairy Sci. 59, 1452-1460.

310 Chaney, A.L., Marbach, E.P., 1962. Modified reagents for determination of urea and ammonia. 311 Clin. Chem. 8, 130-132.

312 Erwin, E.S., Marco, G.J., Emery, E.M., 1961. Volatile fatty acid analyses of blood and rumen 313 fluid by gas chromatography. J. Dairy Sci. 44, 1768-1771.

314 Givens, D.I., Barber, W.P., 1986. In vivo evaluation of spent coffee grounds as a ruminant feed. 315 Agr. Wastes 18, 69-72.

316 Goering, H.K., Van Soest, P.J., 1970. Forage fiber analyses (apparatus, reagents, procedures, and 317 some applications). U.S. Agricultural Research Service.

318 Han, Y.W., 1975. Microbial fermentation of rice straw: nutritive composition and in vitro 319 digestibility of the fermentation products. Appl. Microbiol. 29, 510-514.

320 Han, Y.W., 1978. Microbial utilization of straw (a review). Adv. Appl. Microbiol. 23, 119-153. 
321 Kim, C.H., Kim, G.B., Chang, M.B., Bae, G.S., Paik, I.K., Kil, D.Y., 2012. Effect of dietary 322 supplementation of Lactobacillus-fermented Artemisia princeps on growth performance, meat 323 lipid peroxidation, and intestinal microflora in Hy-line Brown male chickens. Poult. Sci. 91, $324 \quad 2845-2851$.

325 Kim, E.T., Moon, Y.H., Min, K.S., Kim, C.H., Kim, S.C., Ahn, S.K., Lee, S.S., 2013. Changes 326 in microbial diversity, methanogenesis and fermentation characteristics in the rumen in response 327 to medicinal plant extracts. Asian-Australas. J. Anim. Sci. 26, 1289-1294.

328 Kim, M.H., Yun, C.H., Lee, C.H., Ha, J.K., 2012. The effects of fermented soybean meal on 329 immunophysiological and stress-related parameters in Holstein calves after weaning. J. Dairy 330 Sci. 95, 5203-5212.

331 Licitra, G., Hernandez, T.M., Van Soest, P.J., 1996. Standardization of procedures for nitrogen 332 fractionation of ruminant feeds. Anim. Feed Sci. Technol. 57, 347-358.

333 Mahesh, M., Mohini, M., 2013. Biological treatment of crop residues for ruminant feeding: A 334 review. Afr. J. Biotechnol. 12, 4221-4231.

335 McAllister, T.A., Beauchemin, K.A., Alazzeh, A.Y., Baah, J., Teather, R.M., Stanford, K., 2011.

336 Review: The use of direct fed microbials to mitigate pathogens and enhance production in cattle.

337 Can. J. Anim. Sci. 91, 1-19.

338 NRC, 2001. Nutrient requirements of dairy cattle. National Academy Press, Washington, DC, 339 USA.

340 Palmquist, D.L., 1994. The role of dietary fats in efficiency of ruminants. J. Nutr. 124, 1377S341 1382S.

342 Pell, A.N., Schofield, P., 1993. Computerized monitoring of gas production to measure forage 343 digestion in vitro. J. Dairy Sci. 76, 1063-1073. 
344 Puchala, R., Min, B.R., Goetsch, A.L., Sahlu, T., 2005. The effect of a condensed tannin-

345 containing forage on methane emission by goats. J. Anim. Sci. 83, 182-186.

346 Rochfort, S.J., Imsic, M., Jones, R., Trenerry, V.C., Tomkins, B., 2006. Characterization of

347 flavonol conjugates in immature leaves of pak choi [Brassica rapa L. Ssp. chinensis L. (Hanelt.)]

348 by HPLC-DAD and LC-MS/MS. J. Agric. Food Chem. 54, 4855-4860.

349 Salman, F., El-Kadi, R., Abdel-Rahman, H., Ahmed, S., Mohamed, M., Shoukry, M., 2008.

350 Biologically treated sugar beet pulp as a supplement in goat rations. Int. J. Agric. Biol. 10, 412351416.

352 Senevirathne, N.D., Okamoto, T., Takahashi, J., Umetsu, K., Nishida, T., 2012. Effect of mixed 353 microbial culture on fermentation of beverage residues and the effect of the fermented beverage 354 residues on in vitro rumen fermentation and methane production. Int. J. Biosci. Biochem. 355 Bioinforma. 2, 349-353.Seo, S., Lee, S.C., Lee, S.Y., Seo, J.G., Ha, J.K., 2009. Degradation 356 kinetics of carbohydrate fractions of ruminant feeds using automated gas production technique. 357 Asian-Australas. J. Anim. Sci. 22, 356-364.

358 Sikka, S.S., Bakshi, M.P.S., Ichhponani, J.S., 1985. Evaluation in vitro of spent coffee grounds 359 as a livestock feed. Agric. Wastes 13, 315-317.

360 Sikka, S.S., Chawla, J.S., 1986. Effect of feeding spent coffee grounds on the feedlot 361 performance and carcass quality of fattening pigs. Agric. Wastes 18, 305-308.

362 Theodorou, M.K., Williams, B.A., Dhanoa, M.S., McAllan, A.B., France, J., 1994. A simple gas 363 production method using a pressure transducer to determine the fermentation kinetics of 364 ruminant feeds. Anim. Feed Sci. Technol. 48, 185-197. 
365 Tokimoto, T., Kawasaki, N., Nakamura, T., Akutagawa, J., Tanada, S., 2005. Removal of lead

366 ions in drinking water by coffee grounds as vegetable biomass. J. Colloid Interface Sci. 281, 5636761.

368 Van Soest, P.J., Robertson, J.B., Lewis, B.A., 1991. Methods for dietary fiber, neutral detergent 369 fiber, and nonstarch polysaccharides in relation to animal nutrition. J. Dairy Sci. 74, 3583-3597.

370 Wallace, R.J., 2007. Antimicrobial properties of plant secondary metabolites. Proc. Nutr. Soc. $37163,621-629$.

372 Wanapat, M., Polyorach, S., Chanthakhoun, V., Sornsongnern, N., 2011. Yeast-fermented 373 cassava chip protein (YEFECAP) concentrate for lactating dairy cows fed on urea-lime treated 374 rice straw. Livest. Sci. 139, 258-263.

375 Wanapat, M., Kang, S., Polyorach, S., 2013. Development of feeding systems and strategies of 376 supplementation to enhance rumen fermentation and ruminant production in the tropics. J. 377 Anim. Sci. Biotechnol. 4, 32.

378 Xu, C.C., Cai, Y., Zhang, J.G., Ogawa, M., 2007. Fermentation quality and nutritive value of a 379 total mixed ration silage containing coffee grounds at ten or twenty percent of dry matter. J. 380 Anim. Sci. 85, 1024-1029. 
384 Table 1. Chemical composition ( $\mathrm{g} / \mathrm{kg}$, DM basis) and estimated price (KRW/kg DM) of each 385 feed ingredient.

\begin{tabular}{lrrrrrrr}
\hline & \multicolumn{7}{c}{ Feed ingredients $^{\dagger}$} \\
\cline { 2 - 8 } Item & Ryegrass & Corn & SBM & SCG & FSCG & APR & FAPR \\
\hline DM (g/kg as fed) & 954 & 907 & 900 & 550 & 925 & 850 & 932 \\
CP & 81 & 103 & 513 & 138 & 141 & 107 & 103 \\
EE & 8 & 34 & 15 & 136 & 157 & 18 & 17 \\
Ash & 54 & 42 & 62 & 20 & 18 & 91 & 95 \\
NDF & 739 & 116 & 237 & 656 & 792 & 649 & 706 \\
ADF & 481 & 61 & 105 & 451 & 526 & 538 & 523 \\
ADL & 54 & 22 & 26 & 142 & 146 & 99 & 74 \\
NDICP & 46 & 33 & 217 & 105 & 114 & 59 & 47 \\
ADICP & 22 & 32 & 139 & 95 & 100 & 42 & 23 \\
NFC & 164 & 738 & 390 & 155 & 6 & 194 & 127 \\
Feed price* (KRW/kg & 364 & 317 & 660 & 91 & 270 & 235 & 429 \\
DM) & & & & & & & \\
\hline
\end{tabular}

386 †SBM; soybean meal, SCG; spent coffee grounds, FSCG; fermented spent coffee grounds, APR;

387 Artemisia princeps residues, FAPR; fermented Artemisia princeps residues.

388 The prices for ryegrass, corn, and SBM are the average market prices in Korea in 2009. The 389 prices of SCG and APR were obtained from the respective manufacturers (Dongseo Food, Inc., 390 and Ganghwa Agricultural R\&D Center, respectively). For the prices of FSCG and FAPR, the 391 cost for the fermentation process, including the expenses for microbial strains, culture medium, 392 labor, and use of fermenter instruments was calculated and added to their raw prices. 
393 Table 2. Ingredients, analyzed chemical composition (g/kg, DM basis), and estimated cost

394 (KRW/kg DM) of experimental diets.

\begin{tabular}{|c|c|c|c|c|c|}
\hline \multirow[b]{2}{*}{ Items } & \multicolumn{5}{|c|}{ Experimental diets } \\
\hline & Control & SCG & FSCG & APR & FAPR \\
\hline \multicolumn{6}{|l|}{ Ingredients $^{\dagger}$} \\
\hline Ryegrass & 500 & 430 & 408 & 393 & 386 \\
\hline Corn & 432 & 414 & 438 & 445 & 451 \\
\hline SBM & 69 & 56 & 54 & 62 & 63 \\
\hline $\mathrm{SCG}$ & 0 & 100 & 0 & 0 & 0 \\
\hline FSCG & 0 & 0 & 100 & 0 & 0 \\
\hline APR & 0 & 0 & 0 & 100 & 0 \\
\hline FAPR & 0 & 0 & 0 & 0 & 100 \\
\hline \multicolumn{6}{|l|}{ Analyzed chemical composition } \\
\hline $\mathrm{DM}$ & 930 & 929 & 933 & 933 & 926 \\
\hline $\mathrm{CP}$ & 120 & 120 & 120 & 120 & 120 \\
\hline $\mathrm{EE}$ & 20 & 32 & 35 & 21 & 21 \\
\hline Ash & 50 & 46 & 46 & 53 & 53 \\
\hline $\mathrm{NDF}$ & 436 & 444 & 444 & 423 & 432 \\
\hline $\mathrm{ADF}$ & 274 & 283 & 281 & 277 & 272 \\
\hline ADL & 38 & 48 & 48 & 42 & 40 \\
\hline NDICP & 52 & 56 & 57 & 52 & 51 \\
\hline ADICP & 34 & 40 & 40 & 36 & 34 \\
\hline NFC & 427 & 414 & 412 & 435 & 425 \\
\hline TDN1x & 680 & 683 & 687 & 677 & 680 \\
\hline Estimated cost (KRW/kg DM) & 364 & 334 & 350 & 348 & 368 \\
\hline
\end{tabular}

395 †SBM; soybean meal, SCG; spent coffee grounds, FSCG; fermented spent coffee grounds, APR;

396 Artemisia princeps residues, FAPR; fermented Artemisia princeps residues.

397 The SCG, FSCG, APR and FAPR treatments contained $100 \mathrm{~g} / \mathrm{kg}$ of SCG, FSCG, APR, and 398 FAPR, respectively. 

ruminal fluid.

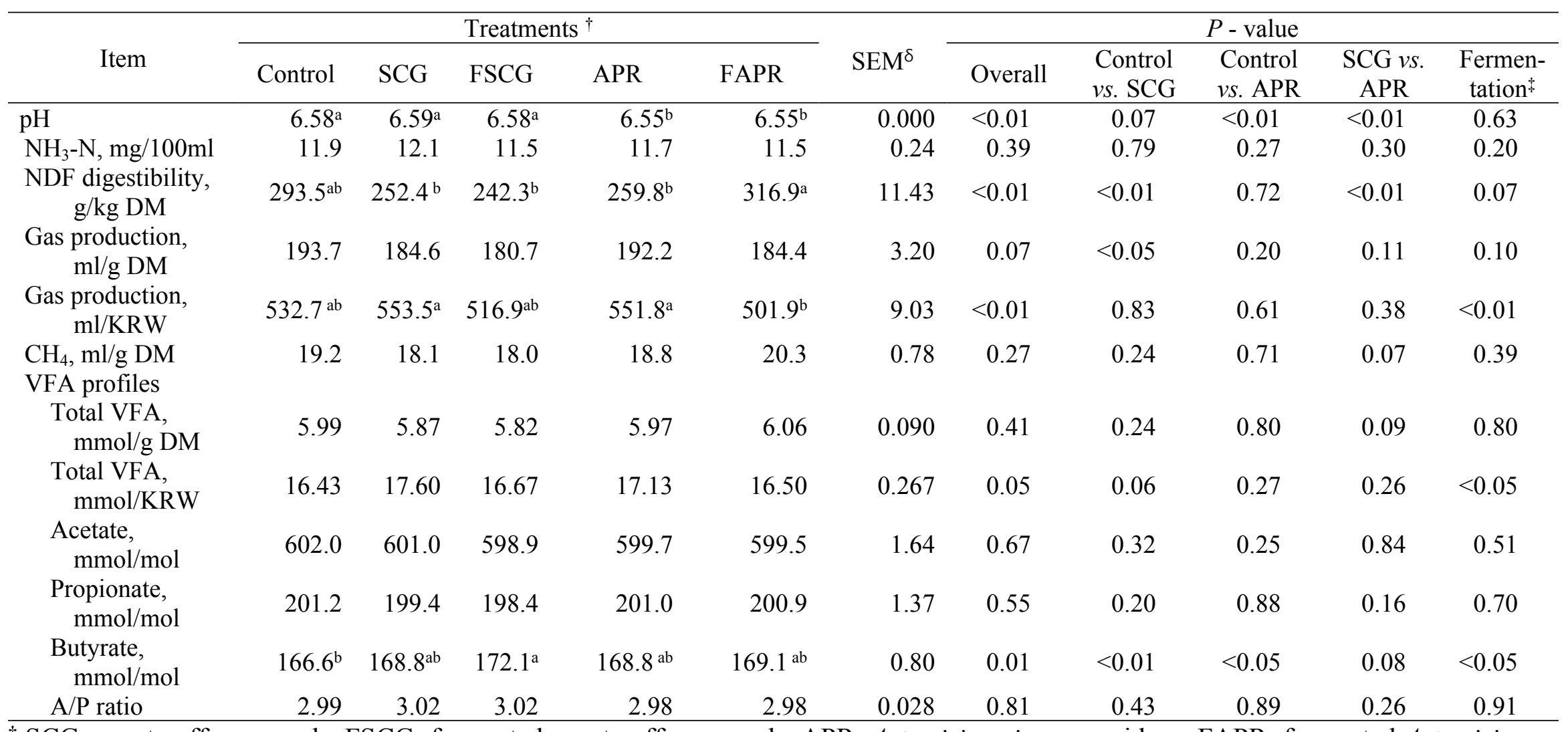

$401 \quad$ SCG; spent coffee grounds, FSCG; fermented spent coffee grounds, APR; Artemisia princeps residues, FAPR; fermented Artemisia

402 princeps residues. The SCG, FSCG, APR and FAPR treatments contained $100 \mathrm{~g} / \mathrm{kg}$ of SCG, FSCG, APR, and FAPR, respectively.

$403 \$$ Statistical difference between fermented and non-fermented substrates (SCG, APR vs. FSCG, FAPR).

404 a,b means that do not have common superscript differ significantly $(P<0.05)$. 


\section{PeerJ}

$\delta$ SEM; standard error of the mean 


\section{Table $\mathbf{1}$ (on next page)}

Table 1 
1 Table 1. Chemical composition ( $\mathrm{g} / \mathrm{kg}$, DM basis) and estimated price (KRW/kg DM) of each 2 feed ingredient.

\begin{tabular}{lrrrrrrr}
\hline & \multicolumn{7}{c}{ Feed ingredients $^{\dagger}$} \\
\cline { 2 - 8 } Item & Ryegrass & Corn & SBM & SCG & FSCG & APR & FAPR \\
\hline DM (g/kg as fed) & 954 & 907 & 900 & 550 & 925 & 850 & 932 \\
CP & 81 & 103 & 513 & 138 & 141 & 107 & 103 \\
EE & 8 & 34 & 15 & 136 & 157 & 18 & 17 \\
Ash & 54 & 42 & 62 & 20 & 18 & 91 & 95 \\
NDF & 739 & 116 & 237 & 656 & 792 & 649 & 706 \\
ADF & 481 & 61 & 105 & 451 & 526 & 538 & 523 \\
ADL & 54 & 22 & 26 & 142 & 146 & 99 & 74 \\
NDICP & 46 & 33 & 217 & 105 & 114 & 59 & 47 \\
ADICP & 22 & 32 & 139 & 95 & 100 & 42 & 23 \\
NFC & 164 & 738 & 390 & 155 & 6 & 194 & 127 \\
Feed price* (KRW/kg & 364 & 317 & 660 & 91 & 270 & 235 & 429 \\
DM) & & & & & & & \\
\hline
\end{tabular}

3 SBM; soybean meal, SCG; spent coffee grounds, FSCG; fermented spent coffee grounds, APR;

4 Artemisia princeps residues, FAPR; fermented Artemisia princeps residues.

5 The prices for ryegrass, corn, and SBM are the average market prices in Korea in 2009. The

6 prices of SCG and APR were obtained from the respective manufacturers (Dongseo Food, Inc.,

7 and Ganghwa Agricultural R\&D Center, respectively). For the prices of FSCG and FAPR, the

8 cost for the fermentation process, including the expenses for microbial strains, culture medium,

9 labor, and use of fermenter instruments was calculated and added to their raw prices. 


\section{Table 2 (on next page)}

Table 2 
1 Table 2. Ingredients, analyzed chemical composition ( $\mathrm{g} / \mathrm{kg}, \mathrm{DM}$ basis), and estimated cost

$2(\mathrm{KRW} / \mathrm{kg} \mathrm{DM})$ of experimental diets.

\begin{tabular}{|c|c|c|c|c|c|}
\hline \multirow[b]{2}{*}{ Items } & \multicolumn{5}{|c|}{ Experimental diets } \\
\hline & Control & SCG & FSCG & APR & FAPR \\
\hline \multicolumn{6}{|l|}{ Ingredients ${ }^{\dagger}$} \\
\hline Ryegrass & 500 & 430 & 408 & 393 & 386 \\
\hline Corn & 432 & 414 & 438 & 445 & 451 \\
\hline SBM & 69 & 56 & 54 & 62 & 63 \\
\hline SCG & 0 & 100 & 0 & 0 & 0 \\
\hline FSCG & 0 & 0 & 100 & 0 & 0 \\
\hline APR & 0 & 0 & 0 & 100 & 0 \\
\hline FAPR & 0 & 0 & 0 & 0 & 100 \\
\hline \multicolumn{6}{|l|}{ Analyzed chemical composition } \\
\hline $\mathrm{DM}$ & 930 & 929 & 933 & 933 & 926 \\
\hline $\mathrm{CP}$ & 120 & 120 & 120 & 120 & 120 \\
\hline $\mathrm{EE}$ & 20 & 32 & 35 & 21 & 21 \\
\hline Ash & 50 & 46 & 46 & 53 & 53 \\
\hline NDF & 436 & 444 & 444 & 423 & 432 \\
\hline $\mathrm{ADF}$ & 274 & 283 & 281 & 277 & 272 \\
\hline ADL & 38 & 48 & 48 & 42 & 40 \\
\hline NDICP & 52 & 56 & 57 & 52 & 51 \\
\hline ADICP & 34 & 40 & 40 & 36 & 34 \\
\hline NFC & 427 & 414 & 412 & 435 & 425 \\
\hline TDN1x & 680 & 683 & 687 & 677 & 680 \\
\hline Estimated cost (KRW/kg DM) & 364 & 334 & 350 & 348 & 368 \\
\hline
\end{tabular}

3 †SBM; soybean meal, SCG; spent coffee grounds, FSCG; fermented spent coffee grounds, APR;

4 Artemisia princeps residues, FAPR; fermented Artemisia princeps residues.

5 The SCG, FSCG, APR and FAPR treatments contained $100 \mathrm{~g} / \mathrm{kg}$ of SCG, FSCG, APR, and

6 FAPR, respectively. 


\section{Table $\mathbf{3}$ (on next page)}

Table 3 
1 Table 3. Fermentation characteristics and $\mathrm{CH}_{4}$ production after $24 \mathrm{~h}$ in vitro incubation of the experimental diets using strained

2 ruminal fluid.

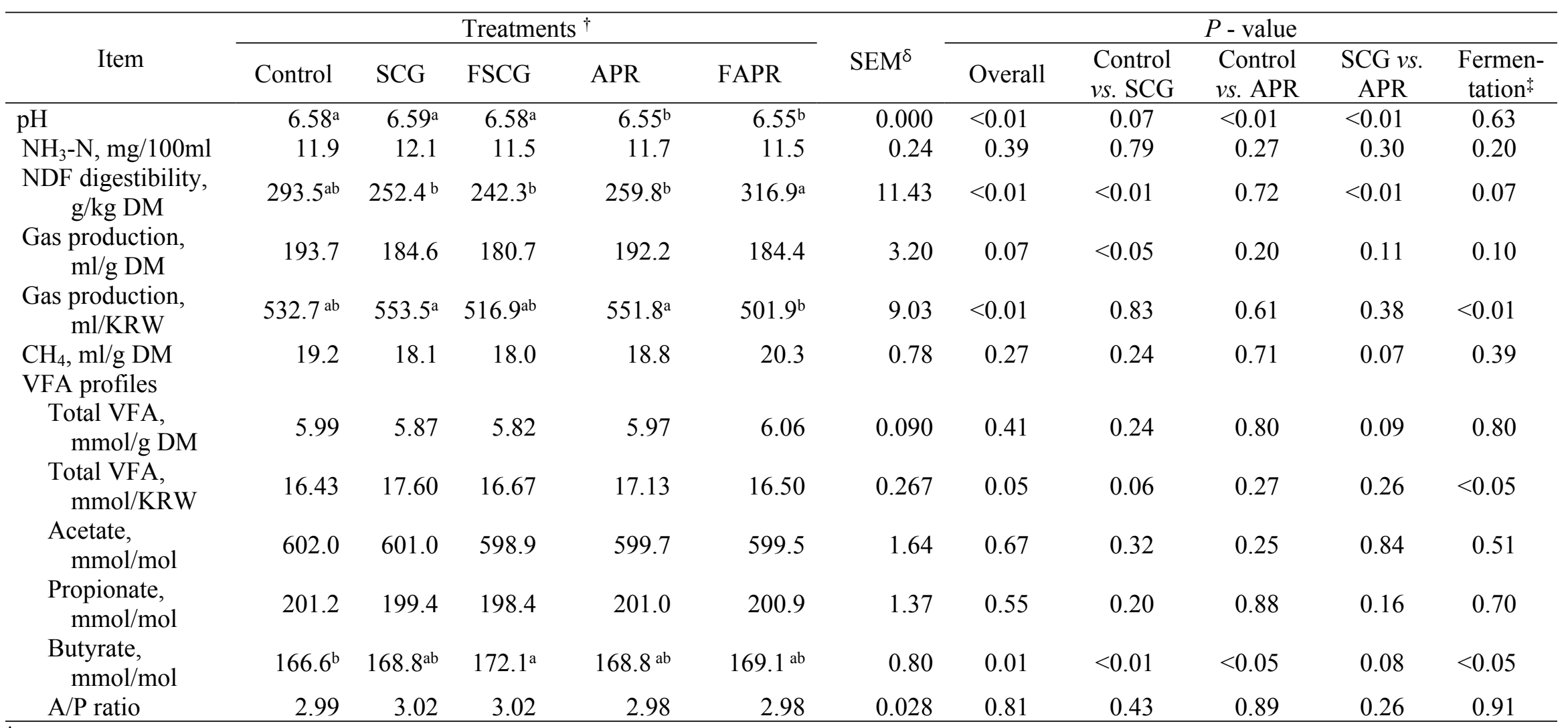

$3 \uparrow$ SCG; spent coffee grounds, FSCG; fermented spent coffee grounds, APR; Artemisia princeps residues, FAPR; fermented Artemisia

4 princeps residues. The SCG, FSCG, APR and FAPR treatments contained $100 \mathrm{~g} / \mathrm{kg}$ of SCG, FSCG, APR, and FAPR, respectively.

$5 \$$ Statistical difference between fermented and non-fermented substrates (SCG, APR vs. FSCG, FAPR).

$6 \quad$ a,b means that do not have common superscript differ significantly $(P<0.05)$. 


\section{PeerJ}

$7 \delta$ SEM; standard error of the mean 